**This is the peer reviewed version of the following article:

Lindsay, R. C. L., Mansour, J. K., Beaudry, J. L., Leach, A. -M., \& Bertrand, M. I. (2009). Sequential lineup presentation: Patterns and policy. Legal \& Criminological Psychology, 14, 13-24. doi:10.1348/135532508X382708

which has been published in final form at http://onlinelibrary.wiley.com/doi/10.1348/135532508X382708/abstract. This article may be used for non-commercial purposes in accordance with Wiley Terms and Conditions for Self-Archiving.

Sequential Lineup Presentation: Patterns and Policy

\author{
R. C. L. Lindsay Jamal K. Mansour \\ Queen's University, Kingston, Ontario, Canada \\ Jennifer L. Beaudry \\ University of South Carolina Beaufort, South Carolina, USA \\ Amy M. Leach \\ University of Ontario Institute of Technology, Ontario, Canada \\ Michelle I. Bertrand \\ Queen’s University Kingston, Ontario, Canada
}

* Correspondence should be addressed to Professor Rod Lindsay, Department of

Psychology, Queen's University, Kingston, Ontario, K7L 3N6, Canada (e-mail:

rod.lindsay@queensu.ca). 


\begin{abstract}
Sequential lineups were offered as an alternative to the traditional simultaneous lineup. Sequential lineups reduce incorrect lineup selections; however, the accompanying loss of correct identifications has resulted in controversy regarding adoption of the technique. We discuss the procedure and research relevant to (1) the pattern of results found using sequential versus simultaneous lineups; (2) reasons (theory) for differences in witness responses; (3) two methodological issues; and (4) implications for policy decisions regarding the adoption of sequential lineups.
\end{abstract}




\section{Sequential Lineup Presentation: Patterns and Policy}

The simultaneous lineup involves showing a witness an array of people or photos comprised of a suspect and known-innocents (fillers). Lineup members are presented together (simultaneously). Witnesses indicate whether they recognize anyone from the lineup and, if so, from where. Selection of a suspect can lead to prosecution and conviction, often in the absence of other evidence (Devlin, 1976). Witnesses frequently select people from a lineup that they have never seen before (Steblay, Dysart, Fulero, \& Lindsay, 2001). Such false positive choices implicate the innocent, deflect attention away from the guilty, and discredit eyewitnesses as a source of evidence.

Wells (1984) argued that witnesses make frequent errors from simultaneous lineups because they employ a 'relative judgment strategy'; choosing the best match to their memory. Research participants often state that they thought the 'target' would be in the lineup because there seemed to be no reason to attempt an identification unless the target was included. In the real world, a similar style of reasoning may lead witnesses to believe that the lineup contains a suspect and that the police have other evidence implicating the suspect. In combination, this situation can lead witnesses to construe the task as deciding which member of the lineup to select rather than whether or not to select someone. The relative judgment strategy generates a high rate of false positive choices whenever the lineup does not contain the perpetrator.

The false positive rate is increased further when lineup instructions suggest that the guilty party is in the lineup (Steblay, 1997), when other lineup members do not match the description of the criminal but the suspect does (Lindsay \& Wells, 1980), and when only the suspect wears clothing matching the clothing described by the witness (Lindsay, 
Wallbridge, \& Drennan, 1987). Perhaps the worst lineup bias is an all-suspect lineup (Wells \& Turtle, 1986). When everyone is a suspect and the witness feels compelled to choose, the procedure can be characterized as a multiple-choice test with no wrong answer.

Lindsay and Wells (1985) designed the sequential lineup to reduce reliance on relative judgments. Witnesses view each lineup member individually and decide, before seeing another lineup member, whether or not that person is the criminal. Once a decision is made, the witness is not allowed to view that lineup member again. The procedure ends either when an identification is made or following the decision for the last lineup member. The sequential lineup procedure eventually included a number of other features designed to limit bias in lineup administration and that ought to be used regardless of how the lineup is presented: single suspect lineups, double-blind testing, confidence statements prior to feedback, and inclusion only of fillers that match the description of the criminal.

\section{The Sequential Lineup Effect}

The false positive rate was significantly lower using sequential (17\%) than simultaneous lineup presentation (43\%; Lindsay \& Wells, 1985). Sequential lineups accomplished their primary purpose: false positive choices were reduced. The rate of correct identification from sequential lineups (50\%) was not significantly lower than the rate from simultaneous lineups (58\%). Lindsay and Turtle (1999) collapsed data across several studies (2753 participants) and reported data that the false positive rate was lower using sequential (20\%) than simultaneous presentation $(45 \%)$ but the correct identification rate also was lower for sequential (42\%) than simultaneous lineups (53\%). 
Lindsay et al. (1991) reported that instruction, clothing, or filler biases increased the false positive rate for simultaneous lineups from $45 \%$ to $66 \%$. The false positive rate for sequential lineups increased from $20 \%$ to $26 \%$. Based on a meta-analysis, Steblay et al. (2001) reported that false positive choices decreased from $51 \%$ with simultaneous lineups to $28 \%$ with sequential lineups, while correct identifications decreased from $50 \%$ with simultaneous lineups to $35 \%$ with sequential lineups.

Despite the initial positive results with sequential lineups, less encouraging results exist. Children are more likely than adults to make false identifications from lineups (Memon \& Gabbert, 2003) and sequential lineups do not consistently reduce their false positive choices (Lindsay, Pozzulo, Craig, Lee, \& Corber, 1997). Sequential lineups reduce false positives by elderly witnesses less and correct identifications more than for young adults (Memon, Bartlett, Rose, \& Gray, 2003). Similarly, facial recognition and eyewitness studies have reported lower correct selection rates and higher false positive rates in cross-race situations (Brigham, Bennett, Meissner, \& Mitchell, 2007). Lindsay, Brigham, Malpass, and Ross (2003) found the sequential lineup effect in all same-race conditions and for all conditions involving witnesses of European ancestry. However, when non-European witnesses attempted to identify targets of European ancestry, sequential lineups generated fewer correct identifications and as many or more false positive choices as simultaneous lineups. Pozzulo demonstrated that correct identifications declined more rapidly for sequential than simultaneous lineups when the criminal's appearance was altered between the time of the crime and the lineup (Pozzulo \& Balfour, 2006; Pozzulo \& Marciniak, 2006).

\section{Differences in the Correct Identification Rate}


Lindsay and Wells (1985) reported that the correct identification rates from sequential and simultaneous lineups were not significantly different. This finding has been replicated in other research (Kneller, Memon, \& Stevenage, 2001; Sporer, 1993). Other studies found significant differences in correct identification rates favouring simultaneous lineups (Parker \& Ryan, 1993). Meta-analyses have settled this issue; on average, correct identification rates are lower using sequential than simultaneous lineups. Debate exists regarding the cause of the sequential lineup effect. The original logic concerning the use of a relative judgment strategy has been challenged by those favouring a signal detection conceptualization (Flowe \& Ebbesen, 2007). Compared to simultaneous lineups, sequential lineups raise the response criterion and thus reduce choosing but do not improve discriminability. Thus, compared with simultaneous lineups, sequential lineups produce more conservative decisions leading people to be less willing to choose anyone from the lineup. The differential decline in correct versus false positive choices occurs because the match to memory is stronger for the person seen than for previously unseen people.

The relative judgment and signal detection perspectives may not be competing explanations; rather, they highlight different facets of the lineup decision-making process. Signal detection theory describes decision-making under conditions of uncertainty. The fact that the data pattern produced by simultaneous and sequential lineups is consistent with those found in other contexts when less and more conservative decision strategies are used is quite limited in its explanatory power for several reasons. First, it is not clear that presenting the same photos sequentially must lead to a more conservative decision. Preschoolers made more choices from sequential than simultaneous lineups (Lindsay et 
al., 1997) and selections did not decline when the target was of European ancestry but the witness was not (Lindsay et al., 2001). When asked why they selected no one from a sequential lineup, debriefed participants often indicated that they were waiting until the 'right' person appeared. Sequential presentation does not seem to make witnesses reluctant to choose; rather, witnesses become less willing to choose just anyone.

Second, the decrease in choosing does not explain how choices are made. Signal detection theory provided little guidance to eyewitness researchers during the early decades of eyewitness research. The relative judgment logic led to a variety of hypotheses about the impact of lineup biases on incorrect lineup decisions. To the extent that it provides connections to a larger literature in the memory area, signal detection theory may be useful in the future. However, signal detection theory is not a theory of memory (Mewhort \& Johns, 2005). Useful contributions are more likely to come from current memory theories (Charman \& Wells, 2007; Meissner, Tredoux, Parker, \& MacLin, 2005).

Third, signal detection theory relies on the calculation of two primary dependent variables (hits and false alarms) from which discrimination (ability to discriminate between previously experienced vs. not experienced events) and response criterion (tendency to make a particular response independent of accuracy) are calculated. Hits are directly comparable to correct identifications. False alarms are another matter. Technically, any incorrect choice of a lineup member is a false alarm. Traditional facial recognition studies most often present faces one at a time (sequentially). Since each decision of whether a face was old (previously seen) or new (not previously seen) is discrete, all mistaken selections are false alarms. When a person chooses someone from a 
six-person lineup, they also are rejecting five others. Is this one decision or six? The issue is complicated when comparing simultaneous lineups where it appears that a single decision is made to sequential lineups where it is clear that multiple decisions are made.

Furthermore, there are alternatives to using signal detection theory. Wells prefers a Bayesian approach to thinking about lineups (Wells \& Lindsay, 1980; Wells \& Turtle, 1986). The Bayesian likelihood (diagnosticity) ratio is similar to discriminability because it combines suspect selection data from both target-present and target-absent conditions. Discriminability also is at least partially reflected in the simple proportion of correct choosers. Response criterion is reflected in the overall proportion of choosers. Many analyses of eyewitness data routinely consider both accuracy and choosing rates as important. Discussing effects in the eyewitness area in terms of correct decisions and choosing rates rather than discriminability and response criterion is accessible to police, lawyers, and judges. For example, a recent study by Lindsay, Semmler, Weber, Brewer, and Lindsay (2006) examined identification accuracy across distance. In signal detection terms, the data indicated declining discriminability but a stable response criterion as distance increased. Police, lawyers, and judges may find such an explanation uninformative. Stating that correct identification rates declined significantly as distance increased, but that choosing rates did not, should be clear to all audiences.

Finally, based on the relative and absolute judgment conceptualization, Clark (2003) developed a model of lineup decision-making. He concluded that a mixture of the two decision processes (relative and absolute) best predicted the data from lineup studies. Gronlund (2004) pitted the signal detection explanation against the relative-absolute 
judgment conceptualization and concluded that the relative-absolute distinction involves something more than just a difference in response criterion.

Overall, the signal detection versus relative-absolute judgment debate is a minor issue. The 'debate' developed because signal detection theory could not account for a lack of difference in correct identifications when false identifications declined. Metaanalyses support a reduction in correct identification using sequential lineups so the data are consistent with both approaches.

\section{Methodological Issues}

\section{Sequential Lineup Technique}

As originally described, the sequential lineup involves a complex set of steps and rules.

One issue is the degree to which all aspects of the procedure must be followed in order to produce the effect. Some useful work has been done on the topic (Lindsay \& Bellinger, 1999; Lindsay, Lea, \& Fulford, 1991; Phillips, McAuliff, Kovera, \& Cutler, 1999). Still, little is known about many issues. Some argue that this is reason enough to abandon adoption of sequential lineups (Malpass, Tredoux, \& McQuiston-Surrett, 2009).

However, every aspect of such a procedure will never be explored. DNA would not be in use today if all questions about the technique had to be answered before it was adopted. Any notion that policy must await complete knowledge is misguided and condemns the criminal justice system to unconscionable delays in implementing new procedures.

Two issues concerning specific research procedures seem worth mentioning: quality of exposure to the target and counterbalancing.

Quality of exposure to targets. The difference in correct identification rates between sequential and simultaneous lineups is smaller using live staged events (Steblay 


\section{SEQUENTIAL LINEUP PRESENTATION: PATTERNS AND POLICY}

et al., 2001). Perhaps higher correct identification rates from sequential lineups and a smaller difference in correct identification rates between sequential and simultaneous lineups occurs when participants have strong memory traces for the criminal as in studies employing live presentation. The critical issue could be the quality of exposure to the target which influences the witness's memory trace for the criminal (Charman \& Wells, 2007; Penrod \& Bornstein, 2007). Penrod (2006; Penrod \& Bornstein, 2007) argued that simultaneous lineups promote guessing and that the correct identification rate from sequential lineups is a better estimate of true recognition because guessing is reduced. When witnesses have good exposure to criminals, they are likely to recognize the criminals when they appear in lineups, regardless of how the lineups are presented. However, when witnesses have poor exposure to criminals, and as a result have weak memory traces or little information to rely on, they will be less willing to make

selections. With sequential lineups this should produce very low choosing rates. Because simultaneous lineups encourage guessing, more selections should occur and, if the target is in the lineup, some will be correct.

Parker and Ryan (1993) reported a correct identification rate of $8 \%$ from a sequential lineup and $42 \%$ from a simultaneous lineup (adults in control conditions). How could only $8 \%$ of participants correctly identify a person they had seen minutes before? The targets appeared on four slides none of which provided a clear frontal view. We think that most participants were guessing. Parker and Ryan are not the sole examples of researchers who have produced stimuli that provide 'poor' exposure to a 


\section{SEQUENTIAL LINEUP PRESENTATION: PATTERNS AND POLICY}

target. Brimacombe, Memon, Lindsay, Pozzulo, Wells, Yuille, and others have used stimuli that provided a less than perfect exposure to the target. Does this mean we should discount their research? Certainly not. Large variations in quality of view occur in real world cases; however, we must systematically vary quality of exposure to discover which variables influence accuracy, how strong the effects are, and whether they differentially influence accuracy from sequential and simultaneous lineups. If a manipulation influences either the strength of memory traces or the amount of information available to witnesses, correct identification rates may decline more rapidly using sequential than simultaneous lineups because the simultaneous lineup capitalizes on guessing. If any information about the target is encoded that will permit the witness to disregard at least some lineup members, simultaneous lineup guesses will be informed and produce accuracy rates above chance. As the detail in memory for targets decreases, it becomes obvious to witnesses that they cannot say that a particular individual definitely is the culprit. Faced with this dilemma, witnesses more often will decline to choose from sequential than simultaneous lineups.

Beaudry, Leach, Mansour, Bertrand, and Lindsay (2006) tested this logic by exposing participants to a videotaped staged crime followed by target-present or targetabsent lineups presented sequentially or simultaneously. Some participants were forewarned that they would be asked to identify the target from the video while others were not. The correct identification rate from simultaneous lineups increased (nonsignificantly) as a result of the forewarning (63\% vs. $72 \%$ ). On the other hand, the 


\section{SEQUENTIAL LINEUP PRESENTATION: PATTERNS AND POLICY}

2

correct identification rate from sequential lineups significantly increased as a result of the forewarning (50\% vs. 74\%). Presumably, participants who expected to identify the target formed a stronger memory trace, which produced a significant increase in correct identifications from sequential lineups.

Counterbalancing. McQuiston-Surrett et al. (2006) reported that the difference in correct identification rates from sequential and simultaneous lineups was systematically related to the laboratory that collected the data. Studies conducted in the Lindsay laboratory found smaller differences in correct identification rates across the two lineup types. Also, a smaller proportion of studies run in our laboratory had counterbalanced target position. Is the assertion that counterbalancing caused smaller differences in correct identification rates reasonable? Consider the following:

(1) Small differences in correct identification rates between sequential and simultaneous lineups have been found in studies that counterbalanced target position (e.g. Kneller, Memon, \& Stevenage, 2001; Lindsay \& Wells, 1985; Sporer, 1993).

(2) Supposedly, communication in the subject pool increases correct identification rates in studies that do not counterbalance. This argument fails for many reasons: (a) Students could be informed about target position in both the simultaneous and sequential conditions. (b) Why would knowledge of target position not inflate incorrect selections in sequential lineup conditions? (c) Ironically, debriefing suggests that participants are more likely to recall the lineup position of the 


\section{SEQUENTIAL LINEUP PRESENTATION: PATTERNS AND POLICY}

person they chose from a simultaneous lineup. (d) Participants always were asked not to discuss the study with others (though they could have ignored their promises). (e) Participants were probed for advanced knowledge of the study. Most had no prior knowledge and, when told anything, participants generally had heard only that the study was interesting. (f) We probed participants about whether or not they believed that the live staged crimes were real. About one third each believed the crime was real, were sceptical, and stated that they believed the crime was not real but had no idea why it had been staged. Analyses separating participants into these three groups revealed no significant differences in performance. (g) A very few students showed signs of nervousness (laughing) when the confederate entered and prior to the crime. Debriefing indicated that these participants had been forewarned of the nature of the research (staged crime and identification). No participant ever indicated that they had been told the position of the target. Of course data from these participants were not included in our results. In retrospect, failure to counterbalance in some studies and report these debriefing results were errors of mine (RL).

(3) The Lindsay laboratory used live staged crimes in all but one of 11 studies comparing simultaneous and sequential lineup presentation. All but two studies conducted by other laboratories used video or slide presentation of the staged crime. Thus counterbalancing differences between our laboratory and others are 


\section{SEQUENTIAL LINEUP PRESENTATION: PATTERNS AND POLICY}

4

completely confounded (and actually smaller) than differences in use of live staged events.

(4) The best argument against the counterbalancing claim is that Steblay's (2007) larger meta-analysis revealed no sign that counterbalancing was associated with the difference in the rates of correct identification from simultaneous versus sequential lineups.

Speculation about differences across laboratories is of very limited value. If someone suspects that failure to counterbalance is a factor in the outcome of sequential versus simultaneous lineup studies, the only scientifically reasonable course of action is to conduct studies that systematically manipulate whether or not target position is counterbalanced. Our speculation about quality of memory also is of questionable value until data are collected to test it.

\section{Policy}

\section{Expectations of False Identification in the 'Real World'}

Reducing false positive choices only matters if target-absent lineups occur in the 'real' world. Filler choices occur in about $20 \%$ of real-world lineups (Behrman \& Davey, 2001; Wright \& McDaid, 1996). Some real-world suspect identifications also will be errors. Thus, at least $20 \%$ of real-world witnesses select innocent people from lineups. However, this does not guarantee that the criminals were not in the lineups. Another approach is to examine cases to see how many suspects are presented per perpetrator. If a single perpetrator commits a crime and the witness fails to identify the suspect, further 


\section{SEQUENTIAL LINEUP PRESENTATION: PATTERNS AND POLICY}

5

investigation may lead to another suspect and lineup. The target-absent rate for the case is at least $50 \%$ (100\% if neither suspect was guilty). One case in the consulting experience of the first author involved 18 suspects in 18 lineups in a case involving a single perpetrator. This logic can be applied to multiple perpetrator cases as well. Another consulting case involved 12 suspects in 12 lineups in a case with only 5 perpetrators. So long as the number of suspects presented in lineups is greater than the number of perpetrators, some suspects were obviously innocent. These two cases produce a minimum innocent-suspect rate of $80 \%$ (24/30). During a police training session, an officer stated that he routinely used twelve-person, all-suspect lineups in cases involving single perpetrators resulting in an innocent suspect rate of at least $91.7 \%$. From about 25 cases during the last 10 years, the overall innocent suspect rate was at least $50 \%$. Of course, these cases are small in number, drawn only from Canadian crimes, involved consulting due to other irregularities (biased lineup procedures), and thus probably are not representative. While others may estimate the proportion of real world lineups containing innocent suspects differently, the reality is that no one has found a valid method of determining the true rate. Moreover, the rate will vary dramatically across time, jurisdiction, crime, and investigating officers.

Loss of correct identifications. Adoption of sequential lineup procedures by police has been increasing (Beaudry \& Lindsay, 2006), particularly since the publication of the NIJ Guide (Technical Working Group, 1999) and the Sophanow inquiry (Cory, 2001). Opposition to sequential lineups is based primarily on fear of lost convictions. 


\section{SEQUENTIAL LINEUP PRESENTATION: PATTERNS AND POLICY}

6

When particularly heinous crimes occur, the thought that the perpetrators may not be punished outrages many. This alone cannot be the deciding factor for policy. No matter how heinous the crime, a 'someone must pay' attitude will only tend to reduce reasonable processing of information by witnesses, police, prosecutors, jurors, and possibly even judges. Coercion will obtain confessions but society rejects this procedure because of the risk of false confession (Kassin \& Gudjonsson, 2004). The possibility that some guilty people will go unpunished is not a sufficient criterion to abandon procedures designed to protect innocent people from wrongful conviction.

One could argue that the number of innocent people convicted on the basis of mistaken identification is unknown but likely to be very small. The absolute number of DNA exoneration cases (about 250 in North America to date) supports this logic. However, there also are good arguments for considering the importance of corroboration as a factor. Both the Devlin (1976) and Cory (2001) commissions concluded that eyewitness identification alone may not be sufficient to prove guilt beyond a reasonable doubt. An Ontario provincial police officer that we work with has an excellent approach to eyewitness cases. He argues that identification focuses interest on a particular person. If the identified person is truly the criminal, corroborating evidence will exist. If such evidence cannot be found, the validity of the identification must be questioned.

Furthermore, many cases involve multiple eyewitnesses (Tollestrup, Turtle, \& Yuille, 1994; Wright \& McDaid, 1996). Paterson and Kemp (2006) found that $86 \%$ of people who witnessed serious crimes indicated that multiple witnesses were present. The 


\section{SEQUENTIAL LINEUP PRESENTATION: PATTERNS AND POLICY}

current focus of attention in the field has been on the probability that an individual eyewitness will identify the criminal. As more witnesses are involved in a case, the probability that none of the witnesses will identify the criminal from the lineup decreases rapidly regardless of the type of lineup used and the diagnosticity of the evidence is enhanced by consistency of response (Clark \& Wells, 2008). Sequential lineups may reduce the number of witnesses identifying suspects rather than eliminating identifications from such cases. Unless criminal-absent lineups are extremely rare, and we believe they are not rare, protecting the innocent is paramount.

\section{Adopting Sequential Lineups.}

If lineups elicit guessing behaviour, a prosecutor would be more accurate stating that the witness 'guessed' the accused was the person seen rather than 'positively identified' the accused. To the extent that no one can know when witnesses guessed and when they actually recognized the suspect, prosecutors and the courts should prefer sequential lineups because it is less likely that the evidence presented resulted from a guess.

Overall, the available evidence supports the conclusion that adopting sequential lineups dramatically reduces false positive choices from target-absent lineups. Targetabsent lineups are certain to occur in real cases (even though the exact rate is unknown). Some loss of correct identification is inevitable if sequential lineups are adopted; but if the loss is the result of reduced guessing this may be a good thing. Courts should not, and should not want to, convict people on the basis of guesses. Furthermore, failure to obtain 


\section{SEQUENTIAL LINEUP PRESENTATION: PATTERNS AND POLICY}

8

an identification does not preclude conviction. If police have sufficient evidence implicating the suspect before the witness attempts the identification, then a case can be made against the suspect without identification evidence. If no case exists without the identification evidence, then there is no corroborating evidence and the risk of wrongful conviction is very high.

\section{The Sequential Lineup is not Good Enough}

Lindsay argued that the sequential lineup is not good enough because the rate of mistaken identification remains too high (Lindsay, 2003; Dupuis \& Lindsay, 2007). The debate concerning sequential lineups is a minor episode in the development of identification procedures. Attempts to improve on the sequential lineup and to develop alternatives have already begun. Levi (1998) argued for the use of very large sequential lineups. Pryke, Lindsay, Dysart, and Dupuis (2004) introduced the multiple independent identification approach where witnesses first attempt an identification from a traditional lineup and then are asked to make additional identification attempts from other lineups such as a body and voice lineup. Pilot work in our laboratory indicates that increasing the size of simultaneous lineups may be a useful tool for equating simultaneous and sequential procedures in terms of false identifications. Of course, the impact on correct identifications also will have to be considered.

\section{Conclusions}

Sequential lineups are superior to traditional simultaneous lineups because they reduce the rate of false positive choices and thus reduce the risk of mistaken 


\section{SEQUENTIAL LINEUP PRESENTATION: PATTERNS AND POLICY}

9

identification and wrongful conviction. However, sequential lineups generally reduce correct identifications relative to simultaneous lineups. We reviewed possible reasons for this and concluded that a quality of exposure explanation is more plausible than a counterbalancing explanation but neither has sufficient empirical support.

There are serious policy implications of choosing one or the other method of lineup administration and this is complicated by factors such as the age and ethnicity of witnesses and perpetrators. Is a loss of correct identifications balanced by a decrease in false positive choices? Should correct identifications based on guesses be considered valid? There are no easy answers to these questions. One last hypothetical example may illustrate several aspects of why we believe that the use of sequential lineups is justified. If you were asked to select someone you know well from a lineup (best friend, parent, sibling, spouse), would you be less likely to make the correct identification if the lineup was presented sequentially rather than simultaneously? If a witness has a strong, clear memory of the criminal, there is no reason to believe that the witness will fail to recognize the criminal regardless of whether the criminal is presented in a sequential or simultaneous lineup. If correct identification rates are less than $100 \%$, then the situation is one where witnesses are prone to error. Meta-analyses and field studies both clearly indicate that eyewitness performance is far from perfect. To the extent that this is the case, a conservative decision strategy is the best policy based on the value system of the Anglo-American criminal justice system. A significant advantage of sequential lineups is 


\section{SEQUENTIAL LINEUP PRESENTATION: PATTERNS AND POLICY}

0

that they produce a pattern of responding that resembles a conservative decision strategy even when the eyewitness is highly motivated to choose. 


\section{SEQUENTIAL LINEUP PRESENTATION: PATTERNS AND POLICY}

\section{References}

Beaudry, J. L., Leach, A. M., Mansour, J. K., Bertrand, M. I., \& Lindsay, R. C. L. (2006, March). The element of surprise: The impact of participants' knowledge of a subsequent lineup task. Paper presented at the meeting of the American Psychology-Law Society, St. Petersburg, Florida.

Beaudry, J. L., \& Lindsay, R. C. L. (2006). Current identification procedure practices: A survey of Ontario police officers. Canadian Journal of Police and Security Services, $4,178-183$.

Behrman, B. W., \& Davey, S. L. (2001). Eyewitness identification in actual criminal cases: An archival analysis. Law and Human Behavior, 25, 475 - 491.

Brigham, J. C., Bennett, L. B., Meissner, C. A., \& Mitchell, T. L. (2007). The influence of race on eyewitness memory. In R. Lindsay, R. Ross, D. Read, \& M. Toglia (Eds). Handbook of eyewitness psychology: Memory for people (Vol. 2, pp. 257281). Mahwah, NJ: Lawrence Erlbaum and Associates.

Charman S., \& Wells, G. L. (2007). Applied lineup theory. In R. Lindsay, R. Ross, D. Read, \& M. Toglia (Eds). Handbook of eyewitness psychology: Memory for people (Vol. 2, pp. 219-254). Mahwah, NJ: Lawrence Erlbaum and Associates.

Clark, S. E. (2003). A memory and decision model for eyewitness identification. Applied Cognitive Psychology, 17, 629-654.

Clark, S. E. \& Wells, G. L. (2008). On the diagnosticity of multiple-witness identifications. Law \& Human Behavior, 32, 402-422. 


\section{SEQUENTIAL LINEUP PRESENTATION: PATTERNS AND POLICY}

2

Cory, P. (2001). The inquiry regarding Thomas Sophonow. Winnipeg, MB: Manitoba Justice.

Devlin, P. (1976). Report to the Secretary of State for the Home Department of the Department Committee on Evidence of Identification in Criminal Cases. London: Her Majesty's Stationery Office.

Dupuis P. R., \& Lindsay, R. C. L. (2007). Radical alternatives to traditional lineups. In R. Lindsay, R. Ross, D. Read, \& M. Toglia (Eds). Handbook of eyewitness psychology: Memory for people (Vol. 2, pp. 179-200). Mahwah, NJ: Lawrence Erlbaum and Associates.

Flowe, H. D., \& Ebbesen, E. B. (2007). The effect of lineup member similarity on recognition accuracy in simultaneous and sequential lineups. Law and Human Behavior, 31, 33-52.

Gronlund, S. D. (2004). Sequential lineups: Shift in criterion or decision strategy? Journal of Applied Psychology, 89, - 234.

Kassin, S. M., \& Gudjonsson, G. H. (2004). The psychology of confessions: A review of the literature and issues. Psychological Science in the Public Interest. Special Issue: The Psychology of Confessions: 5, 33-67.

Kneller, W., Memon, A., \& Stevenage, S. (2001). Simultaneous and sequential lineups: Decision processes of accurate and inaccurate eyewitnesses. Applied Cognitive Psychology, 15, 659-671.

Levi, A. M. (1998). Protecting innocent defendants, nailing the guilty: A modified 


\section{SEQUENTIAL LINEUP PRESENTATION: PATTERNS AND POLICY}

3

sequential lineup. Applied Cognitive Psychology, 12, 265 - 275.

Lindsay, R. C. L. (2003, July). Radical alternatives to traditional identification

procedures. Paper presented at the meeting of the Society for Applied

Research in Memory and Cognition, Aberdeen, Scotland.

Lindsay, R. C. L., \& Bellinger, K. (1999). Alternatives to the sequential lineup:

The importance of controlling the pictures. Journal of Applied Psychology, 84, 315-321.

Lindsay, R. C. L., Brigham, J. C., Malpass, R. S., \& Ross, D. F. (2003, July). Crossrace identification from simultaneous and sequential lineups. Paper presented at the meeting of the Society for Applied Research in Memory and Cognition, Aberdeen, Scotland.

Lindsay, R.C.L., Lea, J., \& Fulford, J. (1991). Sequential lineup presentation: Technique matters. Journal of Applied Psychology, 76, 741-745.

Lindsay, R.C.L., Lea, J.A., Nosworthy, G.J., Fulford, J.A., Hector, J., LeVan, V., \& Seabrook, C. (1991). Biased lineups: Sequential presentation reduces the problem. Journal of Applied Psychology, 76, 796-802.

Lindsay, R.C.L., Pozzulo, J. D., Craig, W., Lee, K., \& Corber, S. (1997). Simultaneous lineups, sequential lineups, and showups: Eyewitness identification decisions of adults and children. Law \& Human Behavior, $21,404-411$.

Lindsay, R. C. L., Semmler, C., Weber, N., Brewer, N., \& Lindsay, M. R. (2006, March). 


\section{SEQUENTIAL LINEUP PRESENTATION: PATTERNS AND POLICY}

4

Distance and eyewitness identification accuracy: opposition to the 15 meter rule. Paper presented at the meeting of the American Psychology-Law Society, St. Petersburg, Florida.

Lindsay, R. C. L., \& Turtle, J. (1999, October). Best practices for suspect identification: Blind sequential lineup procedures. Paper presented at the meeting of the Criminal Investigative Best Practices Symposium, Ottawa, Ontario.

Lindsay, R. C. L., Wallbridge, H., \& Drennan, D. (1987). Do the clothes make the man? An exploration of the effect of lineup attire on eyewitness accuracy. Canadian Journal of Behavioural Science. Special Issue: Forensic Psychology, 19, 463 478.

Lindsay, R. C. L., \& Wells, G. L (1980). What price justice? Exploring the relationship of lineup fairness to identification accuracy, Law and Human Behavior, 4, 303 313.

Lindsay, R. C. L., \& Wells, G. L. (1985). Improving eyewitness identifications from lineups: Simultaneous versus sequential lineup presentation. Journal of Applied Psychology, 70, 556 - 564.

Malpass, R. S., Tredoux, C., \& McQuiston-Surrett, D. (2009). Sequential lineups and public policy. Legal and Criminological Psychology,.

McQuiston-Surrett, D., Malpass, R. S., \& Tredoux, C. G. (2006). Sequential vs. simultaneous lineups: A review of methods, data, and theory. Psychology, Public 


\section{SEQUENTIAL LINEUP PRESENTATION: PATTERNS AND POLICY}

5

Policy, and Law. 12, 137-169.

Meissner, C. A., Tredoux, C., Parker, J. F., \& MacLin, O. (2005). Eyewitness decisions in simultaneous and sequential lineups: A dual-process signal detection theory analysis. Memory \& Cognition, 33, 783-792.

Memon, A., Bartlett, J., Rose, R., \& Gray, C. (2003). The aging eyewitness: Effects of age on face, delay, and source-memory ability, Journals of Gerontology: Series B: Psychological Sciences and Social Sciences, 58B, 338-345.

Memon, A. \& Gabbert, F. (2003). Improving the identification accuracy of senior witnesses: Do prelineup questions and sequential testing help? Journal of Applied Psychology, 88, 341-347.

Mewhort, D. J. K., \& Johns, E. E. (2005). . Sharpening the echo: An iterative-resonance model for short-term recognition memory. Memory, 13, 300-307.

Parker, J. F., \& Ryan, V. (1993). An attempt to reduce guessing behavior in children's and adults' eyewitness identifications. Law \& Human Behavior, 17, 11-26.

Paterson, H. M., \& Kemp, R. I. (2006). Co-witness talk: A survey of eyewitness discussion. Psychology, Crime, \& law, 12, 181-191.

Penrod, S. (2006, March). Eyewitness guessing and choosing. Paper presented at the meeting of the American Psychology-Law Society, St. Petersburg, FL.

Penrod, S., \& Bornstein, B. H. (2007). Generalizing eyewitness reliability research. In R. Lindsay, R. Ross, D. Read, \& M. Toglia (Eds). Handbook of eyewitness psychology: Memory for people (Vol. 2, pp. 529-556). Mahwah, NJ: Lawrence 


\section{SEQUENTIAL LINEUP PRESENTATION: PATTERNS AND POLICY}

6

Erlbaum and Associates.

Phillips, M. R., McAuliff, B. D., Kovera, M. B., \& Cutler, B. L. (1999). Double-blind photoarray administration as a safeguard against investigator bias. Journal of Applied Psychology, 84, 940-951.

Pozzulo, J. D., \& Balfour, J. (2006). Children's and adults' eyewitness identification accuracy when a culprit changes his appearance: Comparing simultaneous and elimination lineup procedures. Legal and Criminological Psychology, 11, 25-34.

Pozzulo, J. D., \& Marciniak, S. (2006). Comparing identification procedures when the perpetrator has changed appearance. Psychology, Crime \& Law, 12, 429-438.

Pryke, S., Lindsay, R. C. L., Dysart, J. E., \& DuPuis, P. (2004). Multiple independent identification decisions: A method of calibrating eyewitness identification accuracy. Journal of Applied Psychology, 89, 73-84.

Sporer, S. L. (1993). Eyewitness identification accuracy, confidence, and decision times in simultaneous and sequential lineups. Journal of Applied Psychology, 78, 22-33

Steblay, N. (1997). Social influence in eyewitness recall: A meta-analytic review of lineup instruction effects. Law \& Human Behavior, 21, 283-297.

Steblay, N. (2007, March). $2001+6:$ An updated meta-analysis of eyewitness lineup performance under sequential versus simultaneous formats. Paper presented at Off the Witness Stand: Using Psychology in the Practice of Justice, CUNY, New York, NY. 


\section{SEQUENTIAL LINEUP PRESENTATION: PATTERNS AND POLICY}

Steblay, N., Dysart, J. D., Fulero, S. \& Lindsay, R. C. L. (2001). Eyewitness accuracy rates in sequential and simultaneous lineup presentation: A meta-analytic comparison. Law \& Human Behavior, 25, 459-474.

Technical Working Group for Eyewitness Evidence (1999). Eyewitness evidence: A guide for law enforcement. Washington, D. C.: United States Department of Justice, Office of Justice Programs, National Institute of Justice.

Tollestrup, P. A., Turtle, J. W. \& Yuille, J. C. (1994). Actual victims and witnesses to robbery and fraud: An archival analysis. In D. F. Ross, J. D. Read, \& M. P. Toglia (Eds.), Adult eyewitness testimony: Current trends and developments. New York: Cambridge University Press, 144-160.

Wells, G. L. (1984). The psychology of lineup identifications. Journal of Applied Social Psychology, 14, 89-103.

Wells, G. L. (1993). What do we know about eyewitness identification? American Psychologist, 48, $553-571$.

Wells, G.L., \& Lindsay, R.C.L. (1980). On estimating the diagnosticity of eyewitness nonidentifications. Psychological Bulletin, 88, 776-784.

Wells, G. L., \& Turtle, J. W. (1986). Eyewitness identification: The importance of lineup models. Psychological Bulletin, 99, 320 - 329.

Wright, D. B. \& McDaid, A. T. (1996). Comparing system and estimator variables using data from real line-ups. Applied Cognitive Psychology, 10, 75-84. 